\title{
THE IMPACT OF TAX REGIMES ON THE EFFECTIVENESS OF R\&D ALLOWANCES - AN INVESTIGATION OF SEPARATE TAXATION AND FORMULA APPORTIONMENT WITHIN THE FRAMEWORK OF R\&D
}

Gazi Bilal YILDIZ ${ }^{1}$

\author{
Hülya ÇELEBi ${ }^{2}$
}

\begin{abstract}
This study investigates the effectiveness of R\&D allowances within the framework of different tax regimes, namely Separate Taxation (ST) and Formula Apportionment (FA). In order to take the characteristics of R\&D activities as well as the importance of the labor in R\&D activities into account, a model within the framework of principalagent setting is designed, where the impact of investments decisions is also investigated. In the model, R\&D allowances are represented by means of expenditure-based allowances. Because of the analytical limitations, non-linear optimization and genetic algorithm are used for the investigation of the model designed. The outcomes show significant differences between ST and FA regarding the effectiveness of R\&D allowances, impact on the compensation of managers and employees as well as on the welfare of owners (or employers). Under both, with and without R\&D, FA enables to achieve a higher total surplus (net profit) compared to ST.
\end{abstract}

Keywords: Management incentives, Tax allowances, Separate Taxation, Formula Apportionment

JEL: H25, J33, 031

\section{Introduction}

Because of the significant contribution of R\&D to the economic growth and innovation governments use different tools to stipulate and attract the R\&D activities or investments in their countries. This paper focuses on R\&D incentives within the framework of enhanced-deduction of R\&D expenditure, which is one of the most used kind of tax incentives for R\&D activities. Here, a juxtaposition is made between Separate Taxation (ST) and Formula Apportionment (FA), where the first mentioned is the widely-used corporate income taxation (CIT) principle, whereas the latter is in practice in USA and Canada and its implementation is intended within the EU. This means a significant geographical enlargement of FA practice. Further, as the R\&D activities are characterized by their labor intensity, the compensation packages play also an important role here. The review of literature shows that R\&D incentives under FA as well as principal-agent setting have been disregarded so far. This gap arises the question: ,What is the impact of R\&D incentives on the management incentives under ST and FA?'. In order to answer this question, we designed a model based on principal-agent setting within the framework of compensation packages and conducted a non-linear optimization. The outcomes show significant differences between ST and FA referring to the content of compensation packages, their reactions to CIT rates and the net profit.

\footnotetext{
1 Asst. Prof. Dr., Hitit University, bilalyildiz@hitit.edu.tr (corresponding author)

2 PhD Candidate, University of Innsbruck, huelya.celebi@gmail.com
} 


\section{Related Literature}

In general, various studies reveal the impact of CIT on the investment decisions. It is to mention that these studies are mainly characterized by their macro-level perspective, where the impact of CIT at intra-firm level has been disregarded so far (see e.g. Buettner et al., 2011; Hellerstein and McLure, 2004). Because of its contribution to the economic growth and sustainability as well as the impact of CIT on the investment decisions (see e.g. Griffith et al., 1995; Hall and Van Reenen, 2000), R\&D incentives show an increasing trend used by governments to attract the R\&D activities and influence the investment behavior of companies. These tools show a wide range of kinds (such as direct subsidies, input and output-oriented tax incentives, allowances and credits), where however the preferential tax treatment (e.g. enhanced deduction) of R\&D expenditures show an increasing trend (see e.g. Apelt et al., 2016). For instance, with its publication, European Commission (2017) amended its proposal for a Common Consolidation Corporate Tax Base (CCCTB) within the EU with the enhanced-deduction of R\&D. In general, CCCTB proposal intend CIT based on 1) a common set of regulations, 2) tax base allocation based on Formula Apportionment, and 3) cross-boarder loss offset. This means a switch from the widely used practice of the sourcebased principle, namely Separate Taxation (ST), which is based on the regulations of jurisdictions, where the corporation is resident. This switch to FA and its appropriateness caused intensive discussions (see e.g. Altshuler and Grubert, 2011; Buettner et al., 2011; Hellerstein and McLure, 2004; Mueller, 2010). Further the implementation of FA will lead to a geographical enlargement of FA practice from USA and Canada to the European Countries. The following two figures gives an overview of ST and FA (within the CCCTB framework) practice.

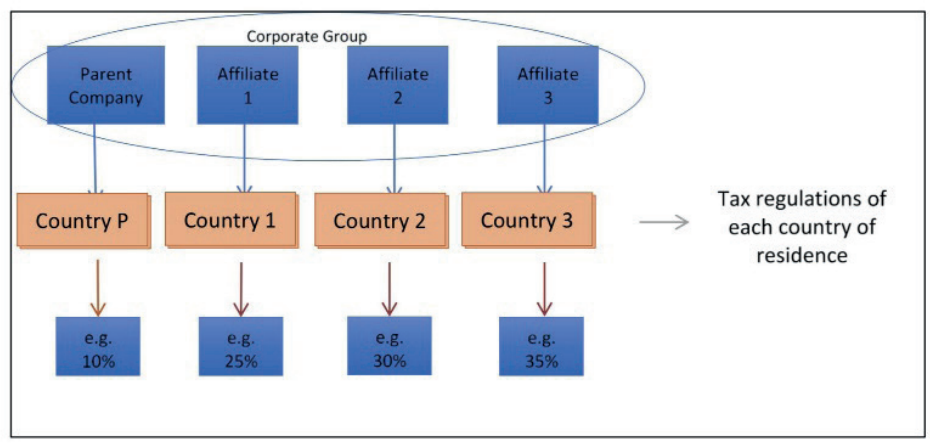

Figure 1. Overview steps of ST 


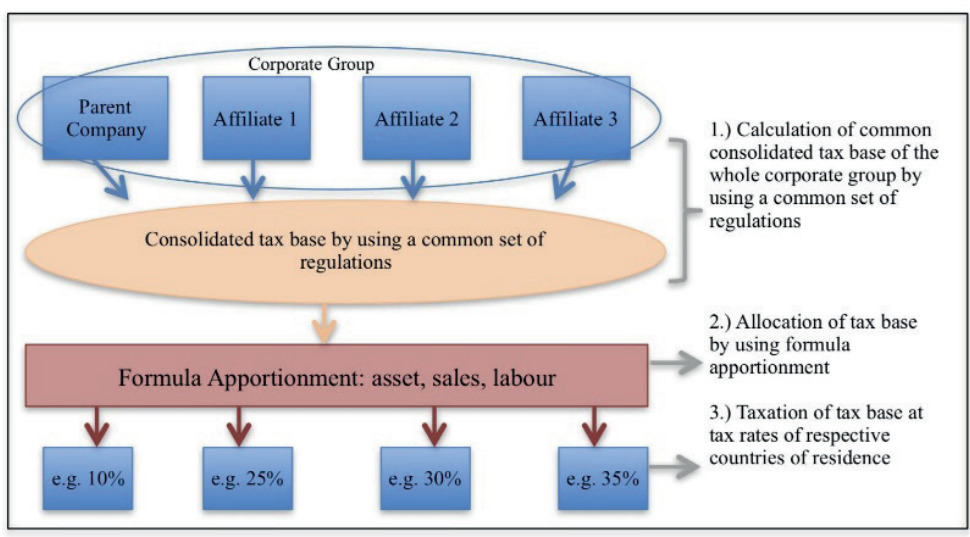

Figure 2. Overview steps of FA (Example of FA within CCCTB (Common Consolidated Corporate Tax Base)

Further, R\&D activities are characterized on one hand by their labor intensity (see e.g. Appelt et al, 2016; D'Andria, 2017) and on the other hand by their information asymmetry and uncertainty. These aspects of R\&D impact the behavior of owners (employers) as well as of managers (employees). Here, the principal-agent setting enables to take these characters of R\&D activities and investments into account. In general, studies investigating the impact of CIT at intra-firm level, namely management compensation packages within the principal-agent setting, are characterized by their focus on ST (see e.g. Voßmerbäumer, 201; Göx, 2008). The review of literature reveal that only one study, namely D'Andria et al. (2016), investigates the impact of R\&D incentives within the principal-agency theory. However, this focuses, as in case of other studies, on ST and takes only wages into account, where the investments remain disregarded.

\section{Model}

In order to answer the research question, we designed a model based on principal-agent setting, which enables us to take the trends and characteristics of R\&D activities into account. The model consists of a multi-jurisdictional corporation (MJE) (principal) with two agents in two different counties (managers or employees). The agents bring output of $x_{i}$ and receive compensation of $w_{i}$ which are formulated as in the following equations:

$x_{i}=a_{i}\left(p_{i}+q_{i} b_{i}\right)+\varepsilon_{i} \quad \varepsilon_{i} \sim N\left(0, \sigma_{i}\right)$

$w_{i}=v_{i} x_{i}+f_{i}$

Here, $p_{i}$ represents the productivity of agents; $a_{i}$ the effort of agents; $q_{i}$ the marginal productivity of investment, $b_{i}$ the amount of investment and $\varepsilon_{i}$ the normally distributed noise term.

Because of the risk and effort averse behavior of agents, the certainty equivalent function $\left(C E\left(w_{i}\right)\right)$ represents their objective function formulated as: 
$C E_{i}=\left(x_{i} v_{i}\right)-\frac{a_{i}^{2}}{2}-\frac{r_{i}}{2} v_{i}^{2} \sigma_{x_{i}}^{2}$

On the other hand, the principal is not able to observe the agents' effort, however she is informed about their objective function $C E\left(w_{i}\right)$ as well as their constraints of participation and incentive, formulated as in the following two equations:

$C E_{i}\left(w_{i}\right)>u$

$a_{i}^{*}=\underset{x}{\operatorname{argmax}} C E_{i}\left(w_{i}\right)$

The aim of the principal is maximize her objective function (TS) by determining the optimal amount of $b_{i}$ and $v_{i}$ in the compensation packages of agents.

When the CIT is not taken into account, TS is formulated as in Eq. (6), whereas Eq. (7) represents TS with CIT under ST without R\&D allowances and Eq. (8) with R\&D allowances (given by $Y_{i}$ ):

$$
\begin{aligned}
& T S=\sum_{i=1}^{2}\left(x_{i}-w_{i}-z_{i}\right) \\
& T S_{S T}=\sum_{i=1}^{2}\left[\left(1-t_{i}\right)\left(x_{i}-w_{i}-z_{i}\right)\right] \\
& T S_{S T_{Y}}=\sum_{i=1}^{2}\left[\left(1-t_{i}\right)\left(x_{i}-w_{i}-z_{i}\right)+\left(Y_{i} t_{i}\left(w_{i}+z_{i}\right)\right)\right]
\end{aligned}
$$

Whereas, when TS of principal is subject to taxation under FA, the factors for the tax base allocation have to be determined firstly. Here, we used two equally weighted formula of wages $\left(w_{i}\right)$ and assets (represented by $b_{i}$ ) given as in the following:

$f a_{i}=\frac{1}{2} \frac{w_{i}}{\sum_{i=1}^{2} w_{i}}+\frac{1}{2} \frac{b_{i}}{\sum_{i=1}^{2} b_{i}}$

The objective function TS is reformulated as in the following, when no R\&D incentives are provided:

$T S_{F A}=\sum_{i=1}^{2}\left[\left(1-t_{i} f a_{i}\right)\left(x_{i}-w_{i}-z_{i}\right)\right]$

In case of R\&D incentives, the tax base is calculated based on the following equation:

TBase $_{F A_{Y}}=\sum_{i=1}^{2}\left[\left(x_{i}-w_{i}-z_{i}\right)-\left(Y_{f}\left(w_{i}+z_{i}\right)\right)\right.$

Hence, under FA TS is reformulated as in the following:

$T S_{F A_{Y}}=\sum_{i=1}^{2}\left[\left(x_{i}-w_{i}-z_{i}\right)-\left(t_{i} f a_{i}\right)\right.$ B Base $\left._{F A_{Y}}\right]$ 


\section{Numerical Analysis}

As a closed-form solution of the model is limited (esp. under FA, under ST the dependency of $b_{i}$ on $v_{i}$ and vice versa) we conducted a numerical analysis for the model represented above. Here we used the following parameters:

$p_{i}=2 ; \quad \sigma_{i}=2 ; c_{i}=0.5 ; q_{i}=1 ; r_{i}=1 ;$

The outcomes of our analysis show that neither the compensation package $\left(v_{i}\right)$ and nor the investment $\left(b_{i}\right)$ are impacted by CIT under ST. By contrary, FA leads to a decrease of $\left(v_{i}\right)$ in the high tax country, and hence offers a higher $v_{i}$ in the low-tax country compared to ST (see Table 1$)^{3}$.

Table 1. Without tax allowances $t_{1}=0.3, t_{2}=0.1$

\begin{tabular}{c|cc|cc|cc}
\hline & \multicolumn{2}{|c|}{ Without CIT } & \multicolumn{2}{c|}{ ST } & \multicolumn{2}{c}{ FA } \\
\hline$v_{1} \mid v_{2}$ & 0.1667 & 0.2 & 0.2 & 0.1668 & 0.186 & 0.1734 \\
$b_{1} \mid b_{2}$ & 1 & 0 & 0 & 1 & 0 & 1 \\
$w_{1} \mid w_{2}$ & 0.6253 & 0.4 & 0.4 & 0.626 & 0.346 & 0.6765 \\
$f_{1} \mid f_{2}$ & 0.3752 & 0.24 & 0.24 & 0.3756 & 0.2076 & 0.4059 \\
$a_{1} \mid a_{2}$ & 0.5 & 0.24 & 0.4 & 0.5 & 0.372 & 0.5202 \\
$x_{1} \mid x_{2}$ & 1.5 & 0.8 & 0.8 & 1.5012 & 0.744 & 1.5606 \\
$f a_{1} \mid f a_{2}$ & 0 & 0 & 0 & 0 & 0.1692 & 0.8308 \\
$t b_{1} \mid t b_{2}$ & 0 & 0 & 0.12 & 0.0875 & 0.0519 & 0.0849 \\
$T S \mid T B$ & 1.025 & - & 0.8425 & 0.2075 & 0.8852 & 0.1368 \\
\hline
\end{tabular}

The following figures represent the outcomes across different CIT rates. As shown in Figure 5, FA leads always to a higher TS, the compensation and its components are more sensitive under FA than under ST (see Figures 4 and 5).

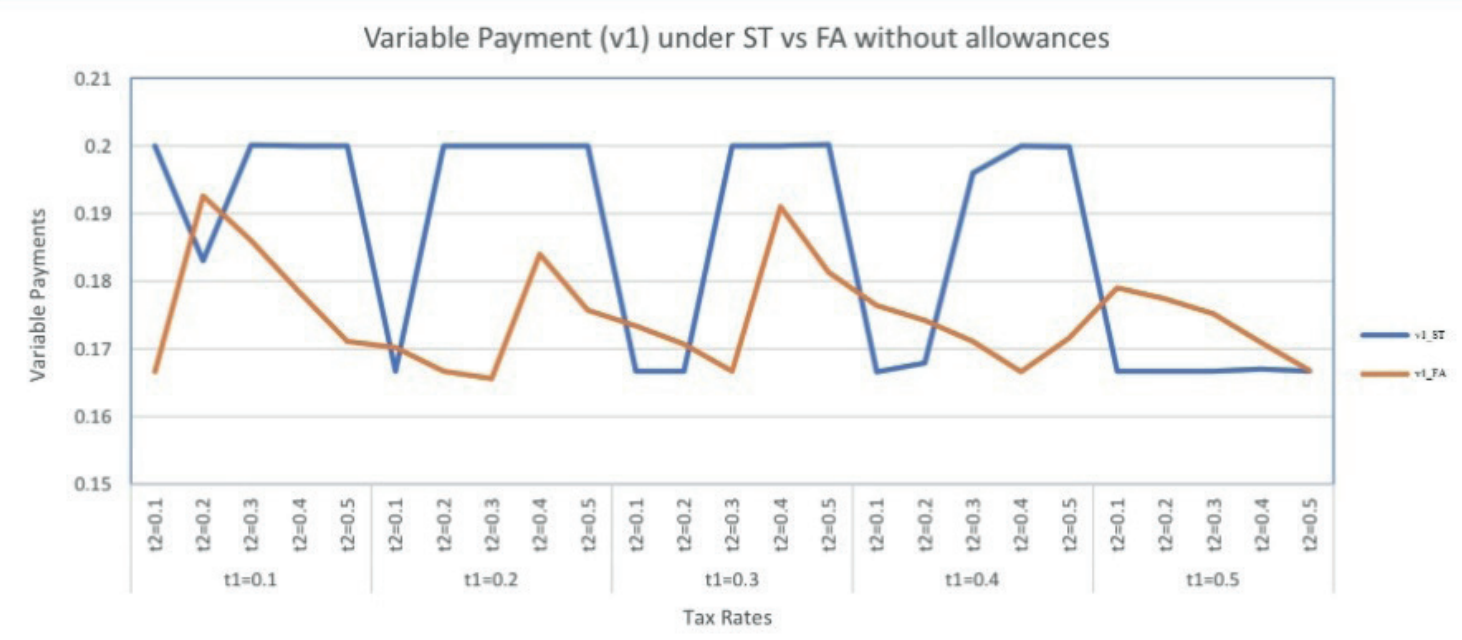

Figure 3. $v_{1}$ under ST vs. FA

\footnotetext{
3 Because of the identical agents assumptions, in case of Without CIT an inverse representation of the outcomes related to $v_{i}$ and $b_{i}$ is possible.
} 


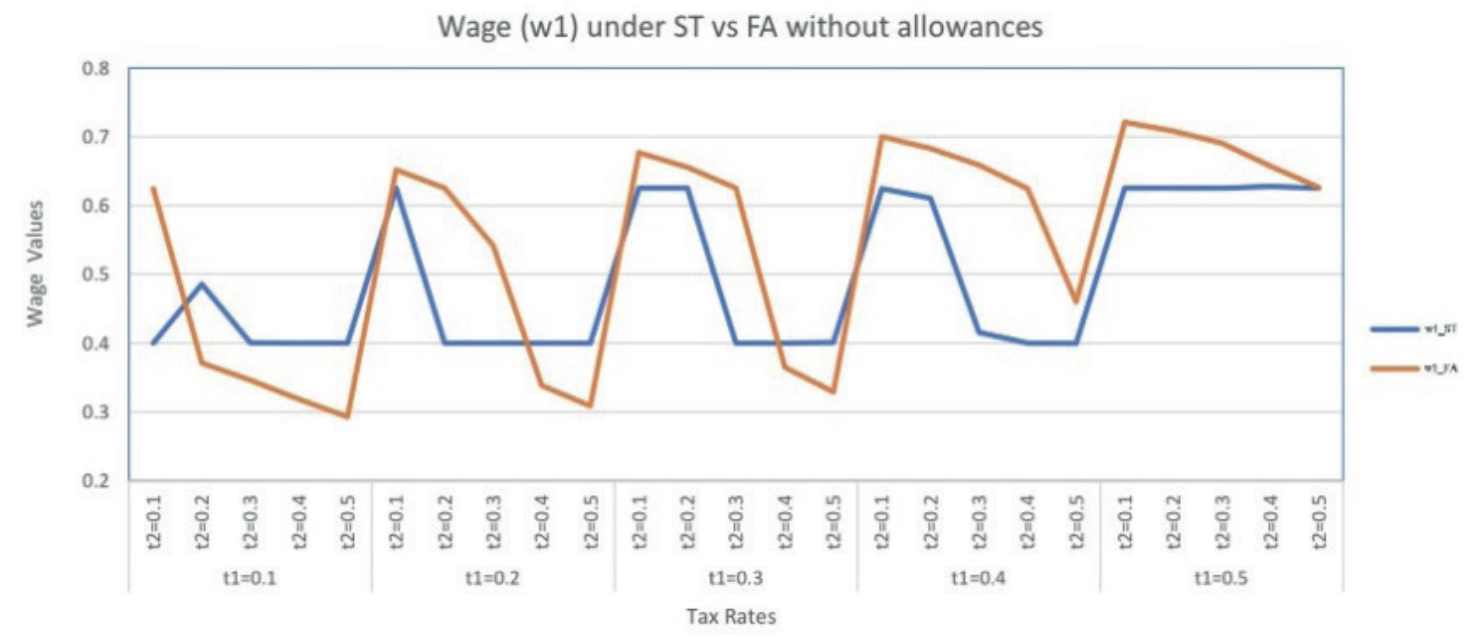

Figure 4. $w_{1}$ under ST vs. FA

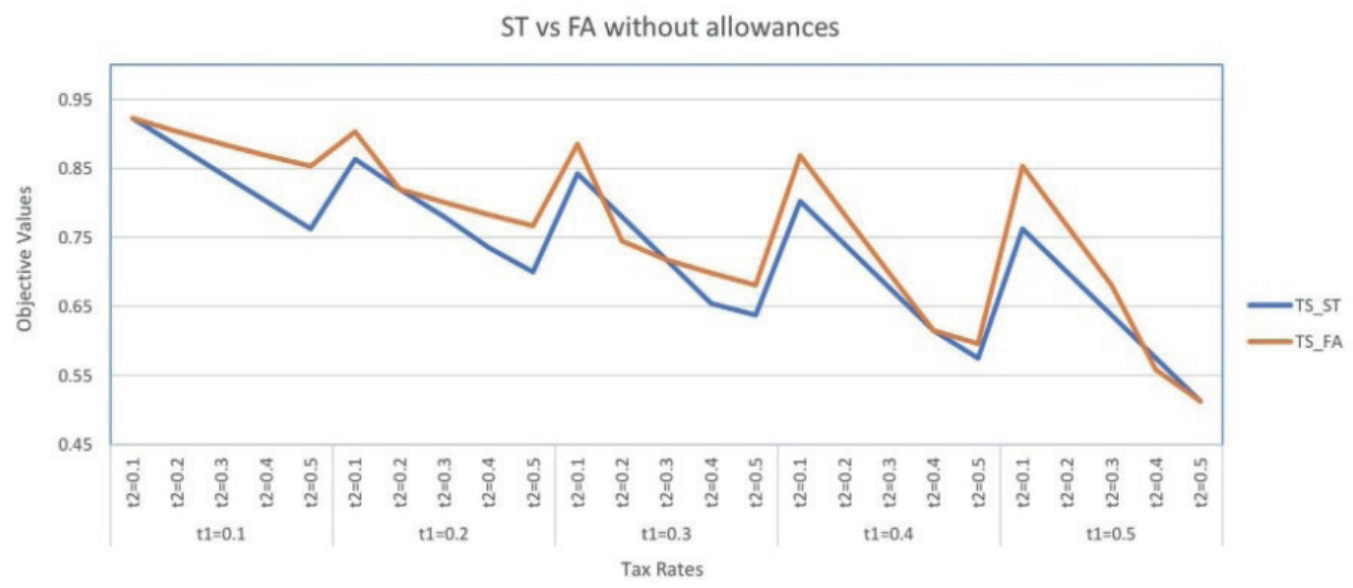

Figure 5. TS under ST vs. FA

Also when taking R\&D incentives into account, FA enables the principal to achieve a higher TS by optimally designing the compensation packages and investment decisions (see Table 2):

Table 2. With tax allowances $\boldsymbol{Y}_{\boldsymbol{i}}=0.25, \boldsymbol{t}_{1}=0.3, \boldsymbol{t}_{2}=0.1$

\begin{tabular}{c|cc|cc}
\hline & \multicolumn{2}{|c|}{ ST } & \multicolumn{2}{c}{ FA } \\
\hline$v_{1} \mid v_{2}$ & 0.1907 & 0.2058 & 0.1993 & 0.1793 \\
$b_{1} \mid b_{2}$ & 1 & 0 & 0.0001 & 0.9999 \\
$w_{1} \mid w_{2}$ & 0.8182 & 0.4235 & 0.3972 & 0.7233 \\
$f_{1} \mid f_{2}$ & 0.4909 & 0.2541 & 0.2383 & 0.434 \\
$a_{1} \mid a_{2}$ & 0.5721 & 0.4116 & 0.3986 & 0.5379 \\
$x_{1} \mid x_{2}$ & 1.7163 & 0.8232 & 0.7972 & 1.6136 \\
$f_{1} \mid f_{2}$ & 0 & 0 & 0.1773 & 0.8227 \\
$t b_{1} \mid t b_{2}$ & 0.1008 & 0.0294 & 0.0359 & 0.0554 \\
$T S \mid T B$ & 0.8815 & 0.1302 & 0.9301 & 0.0913 \\
\hline
\end{tabular}


Across different CITand R\&D incentive rates, the following two figures (see Figures 6 and 7) show that compensation packages under FA and ST vary from each other, however this impacts the TS and tax burden (TB) of principal to a smaller extent (see Figures 8 and 9).

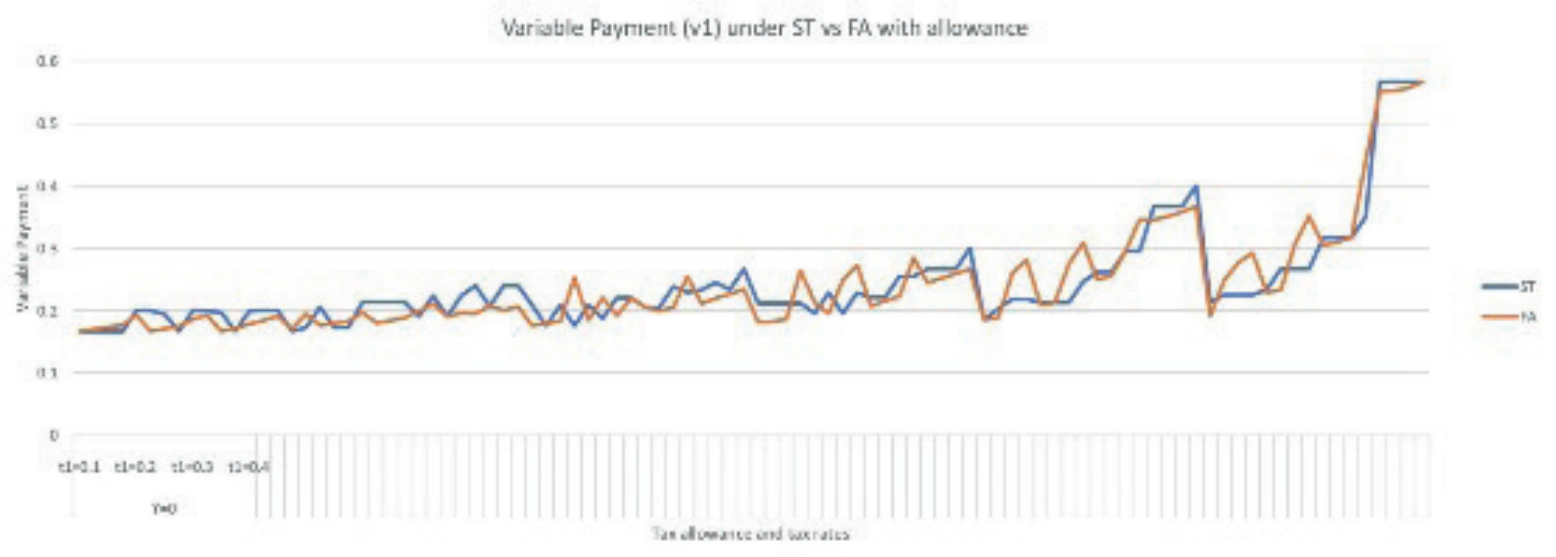

Figure 6. $\boldsymbol{v}_{\mathbf{1}}$ under ST vs. FA with $Y_{i}=\{0,1\}$

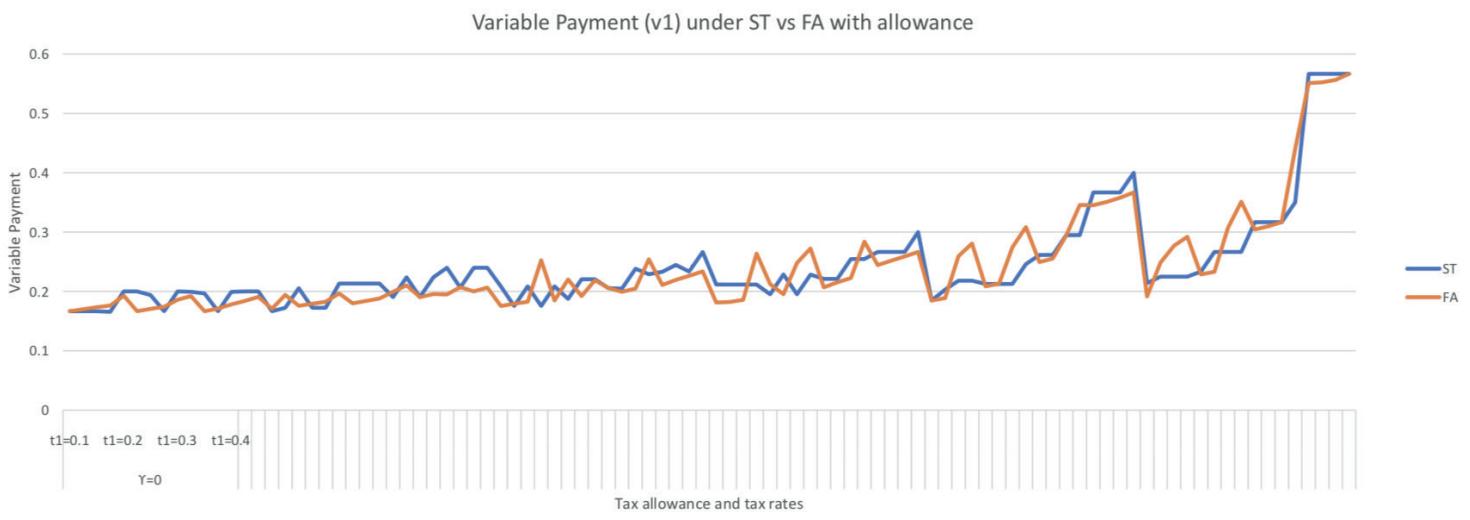

Figure 7. $w_{1}$ under ST vs. FA with $Y_{i}=\{0,1\}$

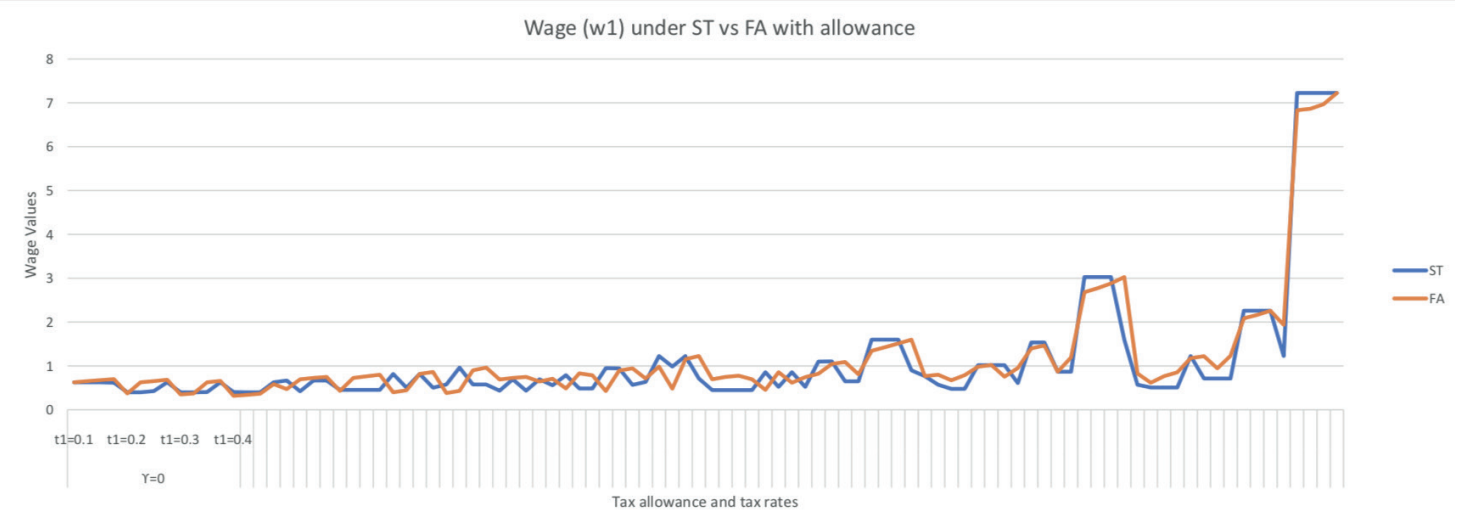

Figure 8. TS under ST vs. FA with $Y_{i}=\{0,1\}$ 


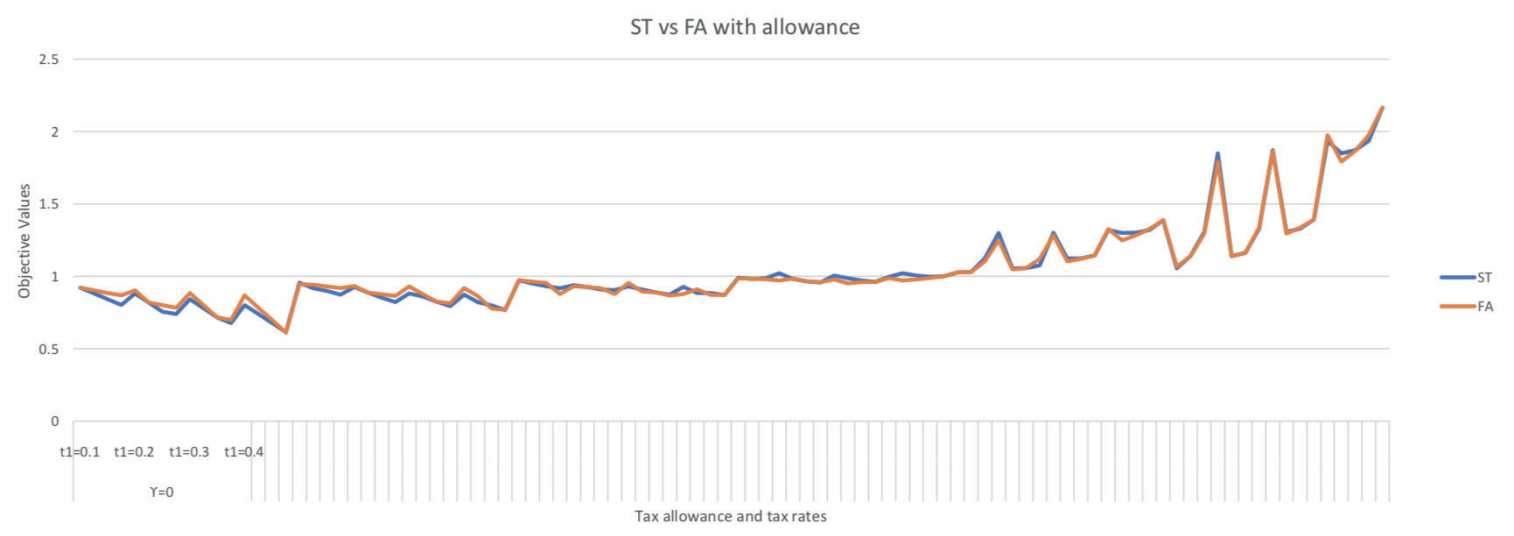

Figure 9. TB under ST vs. FA with $Y_{i}=\{0,1\}$

\section{Conclusion}

This study aimed at analyzing the impact of different tax regimes, namely ST and FA, on the management compensations and investment decisions within the framework of R\&D activities. Here, we investigated the impact of R\&D allowances under different tax regimes. Because of the higher practical relevance, R\&D allowances were represented by expenditure based allowance (enhanced deduction of R\&D expenditures) in the model designed. Further, the model is based on principal-agent setting. Because of the limitations on analytical solvability a numerical analysis is conducted within the framework of non-linear programming. Here, we implement genetic algorithm.

The outcomes show, that CIT shows neutral impact under ST when no R\&D incentives are offered. However, both the agents' as well as the principal's welfares show higher dependency on $\mathrm{CIT}$ rates under FA. An interesting outcome is, that in case of R\&D incentives agents' welfare $\left(w_{i}\right)$ is impacted by CIT to a wider range under FA than it does under ST. However, this gap in $w_{i}$ leads to lower differences in welfare (TS) of principal.

This work contributes to the area of international taxation and existing literature by extending the principal agency-theory and R\&D incentives to the framework of FA. Further, in contrast to the existing literature, we applied non-linear optimization and genetic algorithm in order to investigate the model designed.

\section{References}

Altshuler, R. \& Grubert, H. (2011). "Formula Apportionment: Is it Better than the Current System and are There Better Alternatives?", National Tax Journal, 63 (4/ 2), 1145-1184.

Appelt, S., Bajgar, M., Criscuolo, C. \& Galindo-Rueda, F. (2016). “R\&D Tax Incentives: Evidence on design, incidence and impacts", OECD Science, Technology and Industry Policy Papers, No. 32, OECD Publishing, Paris.

Buettner, T., Riedel, N. \& Runkel M. (2011). "Strategic Consolidation under Formula Apportionment", National Tax Journal, 64 (2/1), 225, 254. 
Cheng, S. (2004). "R\&D Expenditures and CEO Compensation", The Accounting Review, 79(2), 305-328.

D`Andria, D. (2016). "Taxation and Incentives to Innovate: A Principal-Agent Approach", Finanarchiv, 72(1), 96-123.

D’Andria, D., Pontikakis D. \& Skonieczna A. (2017). "Towards a European R\&D incentive? An assessment of R\&D provisions under a Common Corporate Tax Base", TAXUD Taxation Papers, Working Paper, 69.

European Commission (2017). "R\&D tax incentives: How to make them most effective?", Working-Paper Series.

Göx, R. F. (2008). "Tax incentives for inefficient executive pay and reward for luck", Review of Accounting Studies, 13, 452-478.

Griffith, R., Sandler, D. \& Reenen, J. V. (1995). “Tax Incentives for R\&D”, Fiscal Studies, 16(2), 21-44.

Hall, B. \& Van Reenen, J. (2000). "How effective are fiscal incentives for R\&D? A review of the evidence", Research Policy, 29(4-5), 449-469.

Hellerstein, W. \& McLure, C. E. (2004). "The European Commission's report on company income taxation: What the EU can learn from the experience of the US states", International Tax and Public Finance, 11(2), 199-220.

Mueller, P. (2010). "Formula Apportionment - Approaches to Reduce Tax Planning Incentives", SSRN Electronic Journal, https://doi.org/10.2139/ssrn.1730178

Sørensen, P. B. (2004). "Company Tax Reform in the European Union”, International Tax and Public Finance, 11(1), 91-115.

Riedel, N. (2010). "The downside of formula apportionment: evidence on factor demand distortions", International Tax and Public Finance, 17(3), 236-258.

Spremann, K. (1987). Agent and principal. In Agency theory, information, and incentives (pp. 3-37). Springer, Berlin, Heidelberg.

Voßmerbäumer, J. (2013). "Incentive effects and the income tax treatment of employer- provided workplace benefits", Review of Managerial Science, 7, 61-84.

Wolfson, M. A. (1985). "Tax, Incentive, and Risk-Sharing Issues in the Allocation of Property Rights: The Generalized Lease-or-Buy Problem", The Journal of Business, 58, 159-171. 